\title{
Prevalence of Personality Disorders and Clinical Syndromes Using the Millon Clinical Multiaxial Inventory III (MCMI-III) in an Iranian Clinical Sample
}

\author{
Mahboubeh Dadfar, ${ }^{1, *}$, David Lester ${ }^{2}$ \\ ${ }^{1}$ School of Behavioral Sciences and Mental Health-Tehran Institute of Psychiatry, International Campus, School of Public Health, Iran \\ University of Medical Sciences, Tehran, Iran \\ ${ }^{2}$ Psychology Program, Stockton University, Galloway, NJ, USA \\ Email address: \\ mahboubehdadfar@yahoo.com (M. Dadfar), mahboubehdadfar@gmail.com (M. Dadfar), David.Lester@stockton.edu (D. Lester), \\ lesterd@stockton.edu (D. Lester) \\ ${ }^{*}$ Corresponding author
}

\section{To cite this article:}

Mahboubeh Dadfar, David Lester. Prevalence of Personality Disorders and Clinical Syndromes Using the Millon Clinical Multiaxial Inventory III (MCMI-III) in an Iranian Clinical Sample. International Journal of Biomedical Engineering and Clinical Science. Vol. 3, No. 4, 2017, pp. 36-47. doi: 10.11648/j.ijbecs.20170304.13

Received: September 2, 2016; Accepted: October 7, 2016; Published: October 19, 2017

\begin{abstract}
Personality objective inventories are commonly used for diagnosis of personality disorders. Personality assessment is effective in diagnosis, prognosis and treatment of psychiatric outpatients and in patients. Comorbid personality disorders and clinical syndromes may be more worth condition of the patients. The present study aimed to examine the diagnosis of personality disorders and clinical syndromes using the Farsi version of Millon Clinical Multiaxial Inventory III (3rd ed.; MCMI-III) in Iranian psychiatric outpatients. This was a descriptive cross-sectional study. The subjects of the project were 737 psychiatric outpatients. They were referred to the psychiatric and psychological clinics at the School of Behavioral Sciences and Mental Health-Tehran Institute of Psychiatry affiliated to Iran University of Medical Sciences, Tehran, Iran. The subjects were selected using convenience sampling during years of 2010-2015 and evaluated by the MCMI-III computerized Farsi version. Data were analyzed by descriptive methods and $t$ test using SPSS/WIN 16.0 program. Results showed that the most frequent of personality disorders were Depressive (2B), Compulsive (7), and Histrionic (4); with double code types of Depressive- Dependent (2B3); and Histrionic- Depressive (42B) combinations. The most frequent of moderate clinical syndrome were Anxiety (A), and Dysthymia (D) and the severe syndromes was Thought Disorder (SS); with double codes of clinical syndromes of Anxiety- PostTraumatic Stress Disorder (AR). There were significant differences between women and men patients in mean scores of some MCMI-III scales. Women had higher scores in Validity Scales of Disclosure (X) and Debasement (Z) than men. Depressive, Passive-Aggressive (Negativistic) (8A), Self-Defeating (8B) and Borderline (C) personality disorders were the most common in women than men. By contrast, Compulsive (7) personality disorder was the most common in men compare to women. Anxiety, Somatoform (H), Bipolar: Manic (N), Dysthymia (D), and Post-Traumatic Stress Disorder (R), Thought Disorder (SS), and Major Depression Disorder (CC) were the most common in women than men. The prevalence of diagnosis personality patterns and clinical syndromes in Iranian psychiatric outpatients is high and this should be taken into account in their assessment and treatment planning. Using of available sample and lack of random sample; possibility of comorbidity of other mental disorders with main diagnosis are limitations of the study. Utilization of item response theory (IRT); Structural Clinical Interviews for DSM Axis I and Axis II (SCID-I and SCID-II) along with MCMI-III; and MCMI-IV in an Iranian clinical sample are recommended.
\end{abstract}

Keywords: Psychiatric Outpatients, Axis I, Axis II, Millon Clinical Multiaxial Inventory III (MCMI-III), Iran

\section{Introduction}

The first step in the treatment of mental disorders is precise diagnosis for appropriate treatment plan. Psychologists and psychiatrists have tried to using of methods such as precise systems of diseases classification 
and construction of instruments for diagnosis. Differential diagnosis, determination of effectiveness of treatment interventions and treatment planning for patients are depend on valid diagnostic information. One of diagnostic objective, true-false tools is Millon Clinical Multiaxial Inventory (MCMI) which is based on Millon's personality theory. MCMI has been revised four times: Millon Clinical Multiaxial Inventory-First Edition (MCMI-I), Millon Clinical Multiaxial Inventory- Second Edition (MCMI-II), Millon Clinical Multiaxial Inventory- Third Edition (MCMI-III), and Millon Clinical Multiaxial Inventory- Fourth Edition (MCMI- IV) (Groth-Marnat, \& wright, 2016).

Diagnostic accuracy of the MCMI-I is less than DSM-III$\mathrm{R}$ diagnoses, especially for psychotic disorders. The MCMI-I and MCMI-II minimized the frequency of psychotic disorders and overrated the frequency of personality disorders (PD) and nonpsychotic disorders in psychiatric outpatients (Inch, \& Crossley, 1993). Libb, Murray, and Alarcon (1992) indicated that MCMI-II is tied to DSM-III-R diagnoses, and is a diagnostic tool and provides useful information related to diagnostic categories in the most of psychiatric situations. MCMI-II has been used in diagnosis of PDs but utility of the MCMI-III is investigating in differentiation between Axis I clinical syndromes). MCMI-III is tied to the fourth edition of the Diagnostic and Statistical Manual of Mental Disorders, or DSM-IV diagnoses. It was normed on clinical samples. MCMI-III base rates differ among clinical settings (Grove, \& Vrieze, 2009).

MCMI-III introduced in 1994 August at congress of American Psychological Association (APA) (American Psychological Association, 2013). MCMI-III is used in research and clinical settings for psychological assessment of clinical and PDs (Grove, \& Vrieze, 2009; Hopwood, \& Bornstein, 2014); and in corrections settings for offenders (Retzlaff, Stoner, \& Kleinsasser, 2002). MCMI-III is a valid inventory and useful for stable diagnosis of PDs and transient clinical syndromes for $18+$ adults. It was made on the basis of a three-stage validation process proposed by Loevinger (1957) includes sustentative validity (internal); structural validity; and convergent or discriminative validity (external) (Sharifi, Moulavi, \& Namdari, 2008; Chegini, Delavar, \& Gharraee, 2013).

MCMI-III currently is used to access to diagnostic information of mental disorders by many clinicians. It is based on the theoretical and scientific foundations and has advantages and limitations, and its results are a guide for clinicians. MCMI-III can differentiate clinical from nonclinical populations. Strengths of MCMI-III include relatively brief, easy to administer; easy computer-scoring; good reliability; tied to Millon's theory; tied to DSM-IV dx (including PD); high consistency with DSM-IV; use of both logical and experimental methods in its construction; use of Base Rates (BR); and some research support. Through BR clinicians to be able to predict of having or not having of clinical disorders; and more precise interpret of MCMI-III scores. Milon (1987) indicated two main causes for using of BR: 1) Difference in prevalence rate of disorders; 2) maximize diagnostic efficiency of the MCMI scales and maximize ration of true positive to false positive. Limitations of MCMI-III include difficult to score by hand; descriptions and predictions are more theoretically than empirically based; tied to Millon's personality theory; and interpretation, especially of Axis I disorders, is not as easy as it looks.

Diagnosis of PDs is different due to various used instruments and concern of clinician for considering of this category of disorders (Alnaes, \&, Torgersen, 1988; cited in Hills, 1995; Piersma, \& Boes, 1998). Diagnosis of PDs is time consuming but it is necessary because concordance of PD with Axis I disorder impact on incidence, duration and treatment of the disorder (Widiger, \& Rogers, 1989; Woody et al, 1985; cited in Hills, 1995). PDs impact on around 6\% of the world population, and there is no consistent variation among countries (Tyrer, Mulder, Crawford, Newton-Howes, Simonsen, et al, 2010).

Prevalence and comorbidity of Axis I and Axis II psychiatric diagnosis, using different instrument, have reported in various studies. For example, on the MCMI-II, Dadfar (1997) reported that the most common PDs in Iranian obsessive-compulsive outpatients were Cluster C PDs (39\%), especially obsessive-compulsive personality disorder (OCPD) $(0.21 \%)$; and there was no significant difference between the patients and normals in frequency of PDs. Afkham Ebrahimi, and Daneshamooz (2000) used structured clinical interview for DSM and MCMI-II in Iranian psychiatric inpatients and outpatients with a diagnosis of major depression or dysthymia disorders. They reported comorbidity of depression and passive aggressive, schizoid, avoidant, antisocial and dependent PDs in the patients with a diagnosis of major depression or dysthymia disorders. On the MCMI-II, Malakouti, Mehrabi, Bolhari, and Dadfar (2001) indicated there were comorbid PDs in obsessive-compulsive outpatients (35\%), OCPD (50\%), and dependent PD (14\%).

Parvizi Fard, Birashk, Atef Vahid, and Shakeri (2001) reported that $72.3 \%$ of the Iranian addicts met the DSM-I diagnostic criteria for mood and anxiety disorders. The most common disorders were major depression disorder (66\%) and generalized anxiety disorder (12\%). Salehi, Malekian, Haghighi, Jahangard, and Rahimi (2008) reported on DSMIV criteria, $81.3 \%$ of Iranian treatment-seeking substance dependent patients had at least one PD: Schizoid (11.6\%); Obsessive (11.2\%); borderline (10.7\%); antisocial (10.3\%); paranoid (8.1\%); and schizotypal (7.5\%); histrionic, narcissistic, avoidant, dependent PDs (5\% to 7\%). Significant correlates of higher prevalence PDs in the patients were lower level of education, younger age and being married.

Eftekhar Ardebili, Dadfar, and Karimi Kaisami (2004) studied 4000 files of Iranian psychiatric outpatients at Tehran Institute of Psychiatry Clinic during the years of 1996-2000. A total of 648 cases diagnosed based on DSM-IV diagnostic criteria were selected systematic randomly. Results showed that $35.6 \%$ had comorbid psychiatric disorders. The diagnoses comorbid Axis I disorders, according to DSM-IV diagnostic categories, were mood and anxiety disorders $(34.6 \%)$ and mood and substance-related 
disorders $(6.9 \%)$. The comorbidities according to disorders within each of diagnostic categories were major depressive and obsessive-compulsive disorders $(16.0 \%)$, major depressive and dysthymic disorders $(7.8 \%)$, dysthymic and obsessivecompulsive disorders (5.6\%), and obsessive-compulsive disorder and social phobia disorders (3.9\%). Comorbid Axis II disorders diagnosis, according to DSM-IV Clusters A, B, and $\mathrm{C}$, were Clusters $\mathrm{A}$ and $\mathrm{C}(0.4 \%)$. The particular comorbidities according to disorders within each of the Clusters A, B, or $\mathrm{C}$ were histrionic with borderline PDs $(0.9 \%)$ and paranoid with obsessive-compulsive PDs (0.4\%). The comorbid Axis I and Axis II disorders diagnosis were mood disorders with PDs in general (7.8\%) and mood disorders with Cluster B PDs in particular (14.7\%), anxiety disorder with PDs in general (12.6\%) and anxiety disorder with Cluster C PDs in particular (8.7\%), major depressive disorder with Cluster B (4.3\%), and obsessivecompulsive disorder with Cluster C PDs (3.9\%).

Zimmerman, Rothschild, and Chelminski (2005) reported frequency of DSM-IV PDs in psychiatric outpatients and the comorbidity among them, using the Structured Interview for DSM-IV Personality. $31.4 \%$ of the patients were diagnosed with one of the DSM-IV PD; and $45.5 \%$ of patients with personality disorder not otherwise specified (NOS). The most frequent diagnoses were avoidant, borderline and obsessivecompulsive PDs.

The first United States nationally representative survey of the prevalence of PDs using the International Personality Disorder Examination (IPDE), reported that 9.1\% had PD, borderline (1.4\%) and antisocial (0.6\%) PDs and many U.S. people with PDs had comorbid anxiety disorders (e.g., panic disorder, post-traumatic stress disorder), mood disorders (e.g., depression, bipolar disorder), impulse control disorders (e.g., attention deficit hyperactivity disorder), and substance abuse or dependence (Lenzenweger, Lane, Loranger, \& Kessler, 2007).

Thuo, Ndetei, and Maru (2008) reported that 20\% of Kenyan psychiatric inpatients had an Axis II diagnosis $(87 \%$ Cluster B); and the prevalence of Axis II diagnosis in Kenyan psychiatric inpatients was lower than in American and European psychiatric patients.

On the results from the Wave 2 National Epidemiologic Survey on Alcohol and Related Conditions, Grant, Chou, Goldstein, Huang, Stinson, et al (2008) reported that prevalence of lifetime DSM-IV borderline personality disorder (BPD) was $5.9 \%$. There were no differences in the rates of BPD among men (5.6\%) and women (6.2\%). There were comorbid mood and anxiety disorders, bipolar disorder and schizotypal and narcissistic PDs with BPD.

Dadfar, Yekeh Yazdandoost, and Dadfar (2009) evaluated Iranian patients with gender identity disorder (GID) by DSM based clinical interview and MCMI-II. Results showed that the most frequent of personality patterns were Narcissistic (22\%) and Compulsive (29\%); and the most frequent of dual code types were 75 (Compulsive-Narcissictic, 4 cases) and 17 (Schizoied-Compulsive, 2 cases) combinations. Mazaheri Meybodi, Hajebi, and Ghanbari Jolfaei (2014) assessed the frequency of PDs in Iranian GID patients by the MCMI-II. The frequency of PDs was $81.4 \%$. The most frequent was narcissistic PD (57.1\%) and the least was borderline PD. The average number of diagnoses was 3.00 per patient.

Huang, Kotov, de Girolamo, Preti, Angermeyer, et al (2009) estimated are prevalence DSM-IV PDs in the WHO World Mental Health Surveys. 6.1\% had any PD and 3.6\% for Clusters A $1.5 \%$ for Clusters B and $2.7 \%$ for Clusters C. Males, the previously married, and unemployed (Cluster $\mathrm{C}$ ), and the young (Clusters A and B) and the poorly educated significantly elevated PDs. Comorbidity of Axis II with Axis I was high.

Zhang, Wang, Good, Good, Chow, et al (2012) determined prevalence of PDs using two diagnostic systems of multiaxial (DSM-IV) (both self-reported questionnaire and structured clinical interview) and uni-axial diagnostic system (CCMD-3, Chinese Classification and Diagnostic Criteria of Mental Disorders) in psychiatric outpatients in Shanghai, China. 31.93\% were diagnosed on the DSM-IV PD; avoidant $(8.1 \%)$; obsessive-compulsive $(7.6 \%)$; paranoid $(6.0 \%)$, and borderline $(5.8 \%)$ ); and only 9 patients were diagnosed based on the CCMD-3. Correlates of PDs were the younger aged; being single; those who were not raised by their parents; introverted personalities; first-time seekers of psychocounseling treatment; and patients with co-morbid mood or anxiety disorders.

Martin, Walcott, Clarke, Barton, and Hickling (2013) reported that prevalence of PD in general medical hospital patients in Jamaica was $21 \%$ on the consultant DSM IVTR diagnostic criteria for personality disorders, $28 \%$ on the Jamaica Personality Disorder Inventory (JPDI), and $70 \%$ the International Personality Disorder Examination Screening questionnaire (IPDE-S).

de Bernier, Kim, and Sen (2014) in a systematic review prevalence of PDs in community and clinical adult Asian (Chinese, Indian, Japanese and South Korean) populations indicated that personality disorders assessed by diagnostic tools was higher than that by clinical judgment.

Aghaei, and Golparvar (2014) using individual-family characteristics' questionnaire and structured interview on the basis of the checklist of PD symptoms of DSM-IV, reported prevalence PDs among high school Iranian boys were paranoid $(5.9 \%)$; schizoid $(6.7 \%)$; schizotypal (1.3\%); antisocial $(6.9 \%)$; borderline $(8 \%)$; histrionic $(6.4 \%)$; narcissistic (6.1\%); dependent (4\%); and obsessivecompulsive $(9.9 \%)$.

Sadeghirad, Haghdoost, Amin-Esmaeili, Shahsavand Ananloo, Ghaeli, et al (2010) reported that prevalence of major depressive disorder (MDD) $(4.1 \%)$ is high in Iran and women $(12 \%)$ were at the greater risk of the disorder. On the Iranian Mental Health Survey using DSM-IV psychiatric disorders, a validated Persian translation of the Composite International Diagnostic Interview (CIDI; version 2.1); and the Structured Clinical Interview for DSM-IV Axis I disorders (SCID-I), Sharifi, Amin-Esmaeili, Hajebi, Motevalian, Radgoodarzi, et al (2015) reported that 12m0nth prevalence any psychiatric disorders were $23.6 \%$ with 
$26.5 \%$ of women and $20.8 \%$ of men for one or more psychiatric disorders. Any anxiety disorder (15.6\%) was the most prevalent category of psychiatric disorders. MDD was the most common special disorder (12.7\%), then generalized anxiety disorder (5.2\%) and obsessive-compulsive disorder (5.1\%), and psychotic disorder $0.5 \%$. $63.8 \%$ of people with psychiatric disorders had moderate or serious disorder. Correlates of prevalence of 12-month psychiatric disorders were unemployment, being widowed/divorced and urban living. Dadfar, and Kalibatseva (2016) reported that MDD is the most common psychiatric disorders in Iran.

Personality objective inventories are culture bound and have cultural bias, and their results can be different in clinical and non-clinical samples in various countries (Dadfar, Bahrami, Dadfar, \& Younesi, 2010). Nevertheless, personality assessment, using validated instruments, can be effective in the diagnosis, prognosis and treatment of psychiatric patients. Comorbid psychiatric disorders effect on prognosis, psychosocial adjustment and post-surgery satisfaction of psychiatric patients (Huang, Kotov, \& de Girolamo, 2009; Newton-Howes, Tyrer, Anagnostakis, Cooper, \& Bowden-Jones, 2010). Comorbid PDs can impact on the course and treatment of the Axis I disorder (Dadfar, 1997; Dadfar, Malakouti, Bolhari, \& Mehrabi, 2002; Zimmerman, Rothschild, \& Chelminski, 2005). Comorbidity of Axis I and Axis II may affect functioning and help-seeking behaviors (Lenzenweger, Lane, Loranger, \& Kessler, 2007). The PD predicted symptoms after treatment of addiction (Jansson, Hesse, \& Fridell, 2008). Aim of the study was to detect of Pdss and clinical syndromes using the computerized Farsi version of MCMI-III in Iranian psychiatric outpatients.

\section{Methods and Materials}

This was a descriptive cross-sectional study. The subjects of the project were 737 psychiatric outpatients during years of 2010-2015. They were referral clients from Legal Medicine Organization, psychiatric and psychological private offices and counseling centers and Psychological Services for psychological assessment or for treatment; and were referred to the psychiatric and psychological clinics at the School of Behavioral Sciences and Mental Health-Tehran Institute of Psychiatry affiliated to Iran University of Medical Sciences, Tehran, Iran. The subjects were selected using convenience sampling and evaluated by the Millon Clinical Multiaxial Inventory-III (MCMI-III) (Millon, 1994). The MCMI-III computerized Farsi version was administered.

The MCMI-III is a 175 -item true-false inventory; with age range of 18 and older; reading level of 8th grade; administration of paper-and-pencil, computer, or online; completion time of 25-30 minutes; scoring options of Qglobal $^{\mathrm{TM}}$ web-based, Q local ${ }^{\mathrm{TM}}$ software, mail-in scoring, or manual scoring; report options of interpretive and profile reports. MCMI-III is one of the most applicable psychological tests and was translated to many languages and was used in various cross-cultural researches including Iran (Sharifi, Moulavi, \& Namdari, 2008).
Issues related to interpretation of MCMI-III are gender, ethnicity, age, and code types. MCMI-III comprises a total of 3 modifier and 24 clinical scales derived from Millon's personality theory and paralleling Diagnostic and Statistical Manual of Mental Disorders (3 ${ }^{\text {rd }}$ ed.; DSM-III; APA, 1980) and DSM-IV Axis I and Axis II diagnostic categories. The modifier scales serve to identify the respondent's Disclosure $(\mathrm{X})$, Desirability (Y), and Debasement (Z). The clinical scales include 11 Moderate Personality Pathology scales, three Personality Pathology scales, representing greater levels of personality pathology, and 10 Severe Personality Pathology scales (Millon, Davis, \& Millon, 1997; Hsu, 2002). The MCMI-III was chosen because it has a reliable and valid scale for measuring personality disorders. As recommended in the manual, a cutoff score of 85 or higher was used as diagnostic criterion. The Persian version of the MCMI-III had good psychometric (Sharifi, 2007; Sharifi, et al, 2008).

MCMI-III includes 3 validity, 14 clinical personality, and 10 clinical syndrome scales. Scale V (Validity Index) has items $65,110,157 ; 2$ or more true responses - invalid profile; 1 true response - "questionable validity". Validity/modifying indices are Scale X (Disclosure Index); Y (Desirability Index); and $Z$ (Debasement Index). If raw score of Scale $X$ is below 34 - profile is invalid and defensive underreporting; if raw score is above 178 - profile is invalid and exaggeration of symptoms. Scale Y measures of defensive responding; BR above 75 (not necessarily invalid) indicates presenting self in an overly positive, moral, emotionally stable, gregarious manner - "faking good"; and the higher the score, the more the person is concealing. Scale $\mathrm{Z}$ opposites from Desirability Index; BR above 75 - self description is negative, pathological; and above 85 - could be a cry for help. Clinical Personality Scales serve to color or elaborate on Severe Personality Pattern elevations (unless extremely elevated compared with severe scales) (Millon, et al, 1997).

Clinical personality are 1 Schizoid; 2A Avoidant; 2B Depressive; 3 Dependent; 4 Histrionic; 5 Narcissistic; 6 Antisocial; 6B Aggressive (Sadistic); 7 Compulsive; 8A Passive-Aggressive (Negativistic); and 8B Masochistic. Severe personality pathology is S Schizotypal; C Borderline; and $\mathrm{P}$ Paranoid. Clinical syndromes are A Anxiety; $\mathrm{H}$ Somatoform; N Bipolar: Manic; D Dysthymia; B Alcohol Dependence; T Drug Dependence; R PTSD. Severe clinical syndromes are SS Thought Disorder; CC Major Depression; and PP Delusional Disorder (Millon Clinical Multiaxial Inventory-III (MCMI-III, 2014).

Scale elevation is Personality Patterns: BR 70-74 - likely to possess traits of the construct; BR 75-84 - clinically significant personality traits; and BR $85+$ - Personality disorder. Clinical Syndromes: BR 60- 4 - likely to possess some symptoms of the syndrome; BR 75-84 - presence of a syndrome; and BR $85+$ - prominence of syndrome. The BRs' MCMI-III are used to determine of category or diagnostic validity of MCMI-III scales (Retzlaff, 1996).

The most studies have used the MCMI-II, and MCMI-III versions in Iran. For example Khajeh Mogahy (1993) 
validated MCMI-II in Tehran, Iran. Afkham Ebrahimi and Salehi (2000) investigated the convergent validity between clinical and structural interviews and MCMI-II in Iranian clients out-patient clinic. The results revealed mild satisfactory relationship between interview's findings and MCMI-II profiles. They reported that heterogeneity of the symptoms in formation of the Axis II of diagnosis of personality disorder (according to DSM-IV criteria) and complications relevant to the structure of MCMI-II particularly. Sharifi (2002; cited in Sharifi, 2007) validated MCMI-III in Isfahan, Iran. Test-retest reliability coefficients were from 0.82 (for PP Delusional Disorder) to 0.98 (for 1 Schizoid). Chronbach's alpha coefficients were from 0.85 (for B Alcohol Dependence) to 0.97 (for R PTSD). Positive Predictive Powers (PPPs) were from 0.58 (for 4 Histrionic) to 0.83 (for PP Delusional Disorder). Negative Predictive Powers (NPPs) were from 0.93 (for 8A Passive-Aggressive (Negativistic) to 0.99 (for A Anxiety). Overall Predictive Powers (OPPs) were from 0.86 (for D Dysthymia) to 0.93 (for R PTSD).

Sharifi, et al (2008) investigated the diagnostic validity of MCMI-III' Scales in 238 Iranian psychiatric outpatients/inpatients. Using operating characteristics (prevalence, sensitivity and specificity) of MCMI-III Scales, the predictive powers (positive, negative and overall) of the Scales was calculated. The results showed very good diagnostic validity for all MCM-III scales. The MCMI-III Scales had high Positive Predictive Powers (PPPs), Negative Predictive Powers (NPPs) and Overall Predictive Powers (OPPs). The PPPs ranged from 0.92 to 0.97 , and The NPPs ranged from 0.93 to 0.99 also OPPs ranged from 0.58 to 0.83 for all scales.

Eshghabadi (2011) investigated validity of the MCMI-III and the MMPI-2 (Farsi version 71 items short form) scales in 120 patients admitted to psychiatric counseling centers and offices and reported that correlation coefficients between Dysthymia of the MCMI-III and Depression scale of the MMPI-2 (Farsi version SF form) and was 0.54; Paranoia scales of two inventories was 0.50 ; Schizotypal scale of the MCMI-III and Schizophrenia scale of the MMPI-2 was 0.62; and Compulsion scales of two inventories was 0.51 . There was a significant relationship between Alcohol Dependence of the MCMI-III and Schizophrenia scale of the MMPI-2.
There were no significant relationships between with Alcohol Dependence and Drug Dependence of the MCMI-III and other scales of the MMPI-2.

Chegini, Delavar, and Gharraee (2013) determined the psychometric characteristics of MCMI-III in 774 participants (311 psychiatric outpatients/inpatients, 463 normals). Testretest reliability of the MCMI-III was from 0.611 (for $\mathrm{CC}$ Major Depression) to 0.793 (for R PTSD) in psychiatric patients and from 0.795 ( $\mathrm{T}$ Drug Dependence) to 0.972 (for 2B Depressive); and 8B Masochistic. Severe personality pathology is S Schizotypal; C Borderline; and P Paranoid. Clinical syndromes are A Anxiety; H Somatoform; N Bipolar: Manic; D Dysthymia; B Alcohol Dependence; T Drug Dependence) in normals. Chronbach's alpha was from 0.64 (for 7 Compulsive) to 0.89 (for CC Major Depression). The PPPs for personality scales was $0.13-0.47$; for clinical scales was 0.33-0.78: and NPPs was (0.91-0.99), and total discrimination power was 0.77-0.97. 9 factors with eigenvalue more than 1 were found: emotional distress, selfreferring thoughts/paranoid projection, drug abuse, alcoholism, lack of emotional control/inhibition problems, rumination, sociability, trauma, and passivity. They concluded that the MCMI-III could differentiate psychiatric patients from normals.

In present study patients were guaranteed about the confidentiality of the information. All of them gave written informed consent. Data were analyzed by descriptive methods and t test using SPSS/WIN 16.0 program.

\section{Findings}

Results showed range age of the patients was 18-69 years with mean 31.39, SD (8.66). $60.5 \%$ were men, $39.5 \%$ women. Levels of education were $8.8 \%$ less than diploma; $26.9 \%$ diploma; $9.6 \%$ higher than diploma; 35.5\% BA; $11.4 \%$ master; $4.2 \%$ Ph.D. and $3 \%$ other. $45.2 \%$ were single, $52.4 \%$ married.

With BR 75-84, the most frequent of moderate personality disorder were Histrionic (4); Compulsive (7); Narcissistic (5); and Depressive (2B); and the severe personality pathology was Borderline (C); and with $\mathrm{BR} 86+$ the most frequent of moderate personality disorder were Depressive (2B); Compulsive (7); and Histrionic (4) (See Table 1).

Table 1. Distribution of MCMI-III scales elevation in Personality Patterns of the sample $(N=737)$.

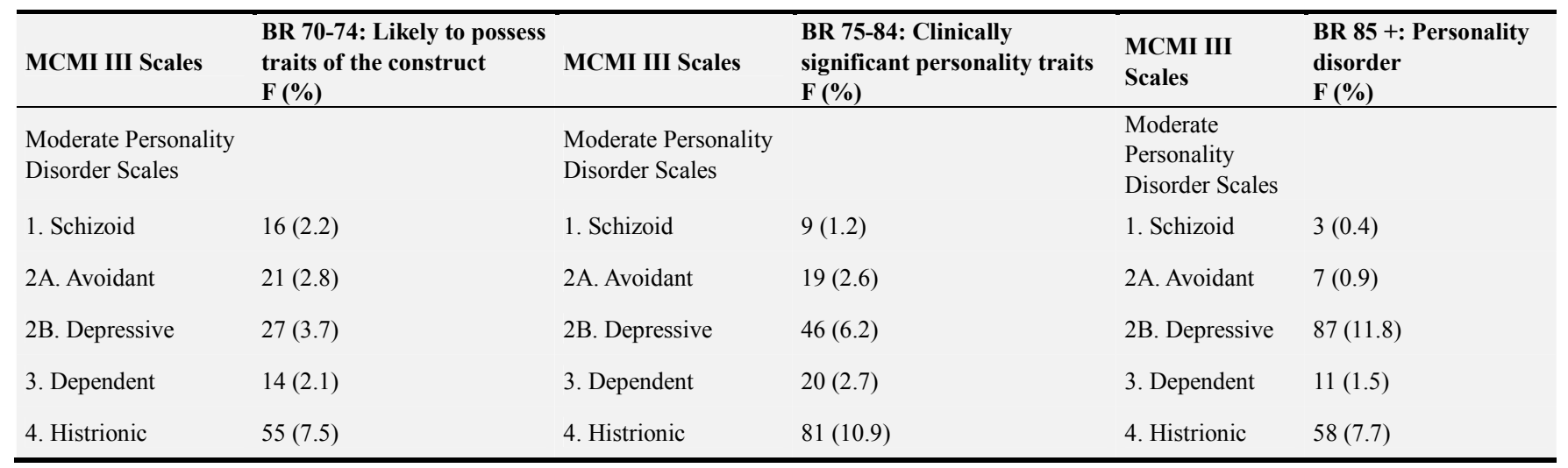




\begin{tabular}{|c|c|c|c|c|c|}
\hline MCMI III Scales & $\begin{array}{l}\text { BR 70-74: Likely to possess } \\
\text { traits of the construct } \\
\text { F (\%) }\end{array}$ & MCMI III Scales & $\begin{array}{l}\text { BR 75-84: Clinically } \\
\text { significant personality traits } \\
\text { F (\%) }\end{array}$ & $\begin{array}{l}\text { MCMI III } \\
\text { Scales }\end{array}$ & $\begin{array}{l}\text { BR 85 +: Personality } \\
\text { disorder } \\
\text { F (\%) }\end{array}$ \\
\hline 5. Narcissistic & $47(6.4)$ & 5. Narcissistic & $60(8.1)$ & 5. Narcissistic & $28(3.8)$ \\
\hline 6A. Antisocial & $16(2.2)$ & 6A. Antisocial & $10(1.4)$ & 6A. Antisocial & $0(0)$ \\
\hline $\begin{array}{l}\text { 6B. Aggressive } \\
\text { (Sadistic) }\end{array}$ & $15(2.0)$ & $\begin{array}{l}\text { 6B. Aggressive } \\
\text { (Sadistic) }\end{array}$ & $11(1.5)$ & $\begin{array}{l}\text { 6B. Aggressive } \\
\text { (Sadistic) }\end{array}$ & $1(0.1)$ \\
\hline 7. Compulsive & $154(20.9)$ & 7. Compulsive & $68(9.2)$ & 7. Compulsive & $60(8.1)$ \\
\hline $\begin{array}{l}\text { 8A. Passive- } \\
\text { Aggressive } \\
\text { (Negativistic) }\end{array}$ & $41(5.7)$ & $\begin{array}{l}\text { 8A. Passive- } \\
\text { Aggressive } \\
\text { (Negativistic) }\end{array}$ & $19(2.6)$ & $\begin{array}{l}\text { 8A. Passive- } \\
\text { Aggressive } \\
\text { (Negativistic) }\end{array}$ & $16(2.2)$ \\
\hline $\begin{array}{l}\text { 8B. Self-Defeating } \\
\text { Severe Personality } \\
\text { Pathology Scales }\end{array}$ & $16(2.2)$ & $\begin{array}{l}\text { 8B. Self-Defeating } \\
\text { Severe Personality } \\
\text { Pathology Scales }\end{array}$ & $0(0)$ & $\begin{array}{l}\text { 8B. Self- } \\
\text { Defeating } \\
\text { Severe } \\
\text { Personality } \\
\text { Pathology Scales }\end{array}$ & $2(0.2)$ \\
\hline S. Schizotypal & $7(0.9)$ & S. Schizotypal & $2(0.2)$ & S. Schizotypal & $4(0.5)$ \\
\hline C. Borderline & $22(2.9)$ & C. Borderline & $10(1.4)$ & C. Borderline & $6(0.8)$ \\
\hline P. Paranoid & $13(1.8)$ & P. Paranoid & $5(0.7)$ & P. Paranoid & $1(0.1)$ \\
\hline
\end{tabular}

Results showed that with BR 75-84, the most frequent of moderate clinical syndrome were Anxiety (A); Bipolar: Manic (N); and Dysthymia: (D) and the severe syndromes was Thought Disorder (SS), and Major Depression (CC); and with BR 86+ the most frequent of moderate clinical syndrome were Anxiety (A); and Dysthymia: (D) and the severe syndromes was Thought Disorder (SS) (See Table 2).

Table 2. Distribution of MCMI-III scales elevation in Clinical Syndromes of the sample ( $N=737)$.

\begin{tabular}{|c|c|c|c|c|c|}
\hline MCMI-III Scales & $\begin{array}{l}\text { BR 60-74: Likely to possess } \\
\text { some symptoms of the } \\
\text { syndrome } \\
\text { F (\%) }\end{array}$ & MCMI-III Scales & $\begin{array}{l}\text { BR 75-84: Presence } \\
\text { of a syndrome } \\
\text { F (\%) }\end{array}$ & MCMI-III Scales & $\begin{array}{l}\text { BR } 85+\text { : Prominence } \\
\text { of syndrome } \\
\text { F (\%) }\end{array}$ \\
\hline $\begin{array}{l}\text { Moderate Clinical } \\
\text { Syndrome Scales }\end{array}$ & & $\begin{array}{l}\text { Moderate Clinical } \\
\text { Syndrome Scales }\end{array}$ & & $\begin{array}{l}\text { Moderate Clinical } \\
\text { Syndrome Scales }\end{array}$ & \\
\hline A. Anxiety & $193(26.2)$ & A. Anxiety & $23(3.1)$ & A. Anxiety & $18(2.4)$ \\
\hline H. Somatoform & $142(19.3)$ & H. Somatoform & $3(0.4)$ & H. Somatoform & $4(0.5)$ \\
\hline N. Bipolar: Manic & $119(16.1)$ & N. Bipolar: Manic & $22(2.9)$ & N. Bipolar: Manic & $5(0.7)$ \\
\hline D. Dysthymia & $135(18.3)$ & D. Dysthymia & $18(2.4)$ & D. Dysthymia & $10(1.4)$ \\
\hline B. Alcohol Dependence & $32(4.3)$ & $\begin{array}{l}\text { B. Alcohol } \\
\text { Dependence }\end{array}$ & $0(0)$ & $\begin{array}{l}\text { B. Alcohol } \\
\text { Dependence }\end{array}$ & $0(0)$ \\
\hline T. Drug Dependence & $55(7.5)$ & T. Drug Dependence & $5(0.7)$ & $\begin{array}{l}\text { T. Drug } \\
\text { Dependence }\end{array}$ & $2(0.2)$ \\
\hline $\begin{array}{l}\text { R. Post-Traumatic Stress } \\
\text { Disorder } \\
\text { Severe Syndrome Scales }\end{array}$ & $137(18.6)$ & $\begin{array}{l}\text { R. Post-Traumatic } \\
\text { Stress Disorder } \\
\text { Severe Syndrome } \\
\text { Scales }\end{array}$ & $9(1.2)$ & $\begin{array}{l}\text { R. Post-Traumatic } \\
\text { Stress Disorder } \\
\text { Severe Syndrome } \\
\text { Scales }\end{array}$ & $9(1.2)$ \\
\hline SS. Thought Disorder & $215(29.2)$ & $\begin{array}{l}\text { SS. Thought } \\
\text { Disorder }\end{array}$ & $34(4.6)$ & $\begin{array}{l}\text { SS. Thought } \\
\text { Disorder }\end{array}$ & $13(1.8)$ \\
\hline CC. Major Depression & $195(26.5)$ & $\begin{array}{l}\text { CC. Major } \\
\text { Depression }\end{array}$ & $18(2.4)$ & $\begin{array}{l}\text { CC. Major } \\
\text { Depression }\end{array}$ & $9(1.2)$ \\
\hline PP. Delusional Disorder & $99(13.4)$ & $\begin{array}{l}\text { PP. Delusional } \\
\text { Disorder }\end{array}$ & $2(0.2)$ & $\begin{array}{l}\text { PP. Delusional } \\
\text { Disorder }\end{array}$ & $4(0.5)$ \\
\hline
\end{tabular}

Findings showed that the most frequent of single code types of PDs were Compulsive (7); Depressive (2B); and Histrionic (4), respectively; and double code types of PDs were Depressive- Dependent (2B3); and Histrionic- Depressive (42B) combinations (See Table 3). 
Table 3. The combinations and frequencies of single/double/triad code types of Personality/ Severe Personality patterns in the sample (N=737).

\begin{tabular}{|c|c|c|}
\hline $\begin{array}{l}\text { Personality patterns } \\
\text { Single code types } \\
\end{array}$ & $\begin{array}{l}\text { Personality patterns } \\
\text { Single code types } \\
\end{array}$ & F (\%) \\
\hline 1 & Schizoid & $2(0.3)$ \\
\hline $2 \mathrm{~A}$ & Avoidant & $2(0.3)$ \\
\hline $2 \mathrm{~B}$ & Depressive & $38(5.2)$ \\
\hline 3 & Dependent & $11(1.5)$ \\
\hline 4 & Histrionic & $30(4.1)$ \\
\hline 5 & Narcissistic & $17(2.3)$ \\
\hline $6 \mathrm{~A}$ & Antisocial & $0(0)$ \\
\hline $6 \mathrm{~B}$ & Aggressive (Sadistic) & $0(0)$ \\
\hline 7 & Compulsive & $42(5.7)$ \\
\hline $8 \mathrm{~A}$ & Passive-Aggressive (Negativistic) & $4(0.5)$ \\
\hline $8 \mathrm{~B}$ & Self-Defeating & $0(0)$ \\
\hline $\begin{array}{l}\text { Severe Personality patterns } \\
\text { Single code types }\end{array}$ & $\begin{array}{l}\text { Severe Personality patterns } \\
\text { Single code types }\end{array}$ & $\mathrm{F}(\%)$ \\
\hline C. Borderline & & $1(0.1)$ \\
\hline $\begin{array}{l}\text { Personality/ Severe Personality patterns } \\
\text { Double code types }\end{array}$ & $\begin{array}{l}\text { Personality/ Severe Personality patterns } \\
\text { Double code types }\end{array}$ & $\mathrm{F}(\%)$ \\
\hline $2 \mathrm{~B} 1$ & Depressive- Schizoid & $1(0.1)$ \\
\hline $2 \mathrm{~B} 2 \mathrm{~A}$ & Depressive- Avoidant & $1(0.1)$ \\
\hline $2 \mathrm{~B} 3$ & Depressive- Dependent & $4(0.5)$ \\
\hline 2B4 & Depressive- Histrionic & $2(0.3)$ \\
\hline 2B8A & Depressive- Negativistic & $2(0.3)$ \\
\hline 2B8B & Depressive- Self-Defeating & $1(0.1)$ \\
\hline $42 \mathrm{~B}$ & Histrionic- Depressive & $4(0.5)$ \\
\hline $72 B$ & Compulsive- Depressive & $1(0.1)$ \\
\hline $8 \mathrm{~A} 2 \mathrm{~B}$ & Negativistic- Depressive & $2(0.3)$ \\
\hline $8 \mathrm{~A} 5$ & Negativistic- Narcissistic & $1(0.1)$ \\
\hline $8 \mathrm{~A} 6 \mathrm{~B}$ & Negativistic- Aggressive (Sadistic) & $1(0.1)$ \\
\hline $8 \mathrm{~B} 2 \mathrm{~B}$ & Self-Defeating- Depressive & $1(0.1)$ \\
\hline 2BS & Depressive- Schizotypal & $2(0.3)$ \\
\hline $8 \mathrm{AC}$ & Negativistic- Borderline & $1(0.1)$ \\
\hline S4 & Schizotypal- Histrionic & $1(0.1)$ \\
\hline $\mathrm{C} 2 \mathrm{~B}$ & Borderline- Depressive & $1(0.1)$ \\
\hline $\mathrm{P} 2 \mathrm{~B}$ & Paranoid - Depressive & $1(0.1)$ \\
\hline $\begin{array}{l}\text { Personality patterns/ Severe Personality patterns } \\
\text { Triad code types }\end{array}$ & $\begin{array}{l}\text { Personality patterns/ Severe Personality patterns } \\
\text { Triad code types }\end{array}$ & $\mathrm{F}(\%)$ \\
\hline $8 \mathrm{~A} 2 \mathrm{~B} 4$ & Negativistic- Depressive- Histrionic & $1(0.1)$ \\
\hline $2 \mathrm{BC} 8 \mathrm{~A}$ & Depressive- Borderline- Negativistic & $1(0.1)$ \\
\hline 2BS8A & Depressive- Schizotypal - Negativistic & $1(0.1)$ \\
\hline
\end{tabular}

Results showed that the most frequent of moderate clinical syndrome were Anxiety (A); and Dysthymia: (D) and the severe syndromes was Thought Disorder (SS). The most frequent of double codes of clinical syndromes were Anxiety- PostTraumatic Stress Disorder (AR) (See Table 4). 
Table 4. The frequencies of single/double/triad code types of Clinical/ Severe Clinical syndromes in the sample (N=737).

\begin{tabular}{lll}
\hline Clinical syndromes Single code types & Clinical syndromes Single code types & F (\%) \\
\hline A & Anxiety & $4(0.5)$ \\
D & Dysthymia & $1(0.1)$ \\
N & Bipolar: Manic & $1(0.1)$ \\
R & Post-Traumatic Stress Disorder & $2(0.3)$ \\
Severe Clinical syndromes Single code types & Severe Clinical syndromes Single code types & F (\%) \\
SS & Thought Disorder & $3(0.4)$ \\
CC & Major Depression & $1(0.1)$ \\
PP & Delusional Disorder & $1(0.1)$ \\
Clinical/ Severe Clinical syndromes Double code types & Clinical/ Severe Clinical syndromes Double code types & F (\%) \\
AR & Anxiety- Post-Traumatic Stress Disorder & $2(0.3)$ \\
AH & Anxiety- Somatoform & $1(0.1)$ \\
RA & Post-Traumatic Stress Disorder- Anxiety & $1(0.1)$ \\
TCC & Drug Dependence- Major Depression & $1(0.1)$ \\
RCC & Post-Traumatic Stress Disorder- Major Depression & $1(0.1)$ \\
SSA & Thought Disorder- Anxiety & $1(0.1)$ \\
SSN & Thought Disorder- Bipolar: Manic & $1(0.1)$ \\
SSCC & Thought Disorder- Major Depression & $1(0.1)$ \\
CCD & Major Depression- Dysthymia & $1(0.1)$ \\
Clinical/ Severe Clinical syndromes Triad codes & Clinical/ Severe Clinical syndromes Triad codes & F (\%) \\
SSAD & Thought Disorder - Anxiety - Dysthymia & $1(0.1)$ \\
CCAH & Major Depression- Anxiety - Somatoform & $1(0.1)$ \\
SSRNA & Thought Disorder - Post-Traumatic Stress Disorder- Bipolar: Manic- Anxiety & $1(0.1)$ \\
\hline
\end{tabular}

There were significant differences between women and men patients in mean scores of some of MCMI-III scales. Women had higher scores in Validity Scales of Disclosure (X) and Debasement (Z) than men. Depressive (2B), Passive-Aggressive (Negativistic) (8A), Self-Defeating (8B) and Borderline (C) PDs were the most common in women than men. Compulsive PD (7) was the most common in men compare to women. Anxiety (A), Somatoform (H), Bipolar: Manic (N), Dysthymia (D), and Post-Traumatic Stress Disorder (R), Thought Disorder (SS), and Major Depression (CC) were the most common in women than men (See Table 5).

Table 5. Mean and Standard Deviation of MCMI III scales.

\begin{tabular}{|c|c|c|c|c|c|}
\hline & M (SD) & M (SD) & M (SD) & & \\
\hline MCMI III Scales & Total & Female & Male & $\mathbf{t}$ & $\mathbf{p}$ \\
\hline \multicolumn{6}{|l|}{ Validity Scales } \\
\hline Disclosure Scale (X) & $64.29(12.87)$ & $66.05(12.36)$ & $63.15(13.06)$ & 3.00 & .003 \\
\hline Desirability Scale (Y) & $65.69(22.05)$ & $64.67(21.02)$ & $66.36(22.69)$ & -1.01 & - \\
\hline Debasement Scale $(Z)$ & $36.67(30.30)$ & $44.03(29.84)$ & $31.87(29.66)$ & 5.42 & .000 \\
\hline \multicolumn{6}{|l|}{ Moderate Personality Disorder Scales } \\
\hline 1. Schizoid & $30.92(22.31)$ & $31.72(22.19)$ & $30.41(22.40)$ & .780 & - \\
\hline 2B. Depressive & $41.85(30.78)$ & $48.30(31.69)$ & $37.65(29.45)$ & 4.65 & .000 \\
\hline 3. Dependent & $28.89(21.59)$ & $32.16(23.53)$ & $26.76(19.97)$ & 3.33 & .001 \\
\hline 4. Histrionic & $52.68(22.66)$ & $55.59(22.31)$ & $50.7822 .71)$ & 2.82 & .005 \\
\hline 5. Narcissistic & $50.31(20.43)$ & $51.45(20.13)$ & $49.56(20.61)$ & 1.22 & - \\
\hline 6A. Antisocial & $35.30(18.93)$ & $35.83(18.78)$ & $34.96(19.04)$ & .610 & - \\
\hline 6B. Aggressive (Sadistic) & $30.83(19.90)$ & $32.72(19.74)$ & $29.60(19.93)$ & 2.08 & - \\
\hline 7. Compulsive & $55.67(23.12)$ & $51.78(23.45)$ & $58.20(22.57)$ & -3.71 & .000 \\
\hline \multicolumn{6}{|l|}{ Severe Personality Pathology Scales } \\
\hline S. Schizotypal & $31.27(20.20)$ & $34.38(20.68)$ & $29.24(19.64)$ & 3.40 & .001 \\
\hline C. Borderline & $37.73(20.11)$ & $42.72(21.01)$ & $34.46(18.82)$ & 5.55 & .000 \\
\hline P. Paranoid & $36.51(21.81)$ & $38.14(21.69)$ & $35.44(21.86)$ & 1.64 & - \\
\hline \multicolumn{6}{|l|}{ Moderate Clinical Syndrome Scales } \\
\hline A. Anxiety & $39.51(25.11)$ & $45.14(25.03)$ & $35.84(24.51)$ & 4.99 & .000 \\
\hline H. Somatoform & $30.91(23.24)$ & $35.89(23.85)$ & $27.65(22.26)$ & 4.77 & .000 \\
\hline N. Bipolar: Manic & $28.20(25.46)$ & $34.28(25.85)$ & $24.23(24.42)$ & 5.33 & .000 \\
\hline D. Dysthymia & $36.63(22.42)$ & $41.86(22.89)$ & $33.21(21.47)$ & 5.20 & .000 \\
\hline B. Alcohol Dependence & $18.89(17.13)$ & $20.27(17.72)$ & $17.99(16.70)$ & 1.77 & - \\
\hline T. Drug Dependence & $24.35(17.77)$ & $25.55(19.26)$ & $23.57(16.70)$ & 1.48 & - \\
\hline R. Post-Traumatic Stress Disorder & $26.26(26.45)$ & $33.32(28.03)$ & $21.66(24.32)$ & 5.98 & .000 \\
\hline \multicolumn{6}{|l|}{ Severe Syndrome Scales } \\
\hline SS. Thought Disorder & $39.54(26.29)$ & $45.12(25.95)$ & $35.91(25.90)$ & 4.71 & .000 \\
\hline CC. Major Depression & $31.37(27.73)$ & $38.39(28.38)$ & $26.79(26.34)$ & 5.67 & .000 \\
\hline
\end{tabular}




\section{Conclusion}

Results of the present study showed that the most frequent of PDs were Depressive (2B), Compulsive (7), and Histrionic (4); with double code types of PDs were DepressiveDependent (2B3); and Histrionic- Depressive (42B) combinations.

Depressive (2B) endures pattern of thoughts, attitudes, behaviors and self-concepts related to depression; shows feels worthless, inadequate, guilty, self-critical; forlorn, discouraged, hopeless; helpless and immobile in solving life's problems; and angry, resentful, pessimistic in relationships. Frequent code types: Clinical: D, N Personality: 1, 2A, 8A, 8B, C. Histrionic (4) shows dramatic, colorful and emotional; tolerance for boredom is low; describe self as active, egocentric, exhibitionistic, flighty, extroverted, flirtatious; charming and outgoing, attention seeking' can be loud, demanding and uncontrollable; strong needs for dependency; can be warm, emotionally responsive, good sense of humor, adaptable; and good social adjustment, low levels of distress. Frequent code types: Clinical: A, H, B, T; Personality: 3, 5, 6A, 7, 8A. Compulsive (7) coincides with DSM IV Obsessive-compulsive personality disorder; conformity, discipline, self-restraint and formality; adheres strictly to social norms; conscientious, well prepared, righteous and meticulous; fears social disapproval, deny hostility; disciplined, self-restraint, high demands on themselves; overt passivity and public compliance; loyalty, prudence, consistency, predictability; approaches problems with maturity and competence; high achievers- rarely report psychiatric distress. Frequent code types: Clinical: A, D; Personality: 1, 2A, 2B, 4, 5, 6A.

Unlike normal people, due to some factors, reliability of mental patients reports about their personality function could be doubtful. There are some documents showing theses effects are more prominent in personality self-reports inventories than interviews (Zimmerman, \& Coryell, 1990; cited in Bernstien, Kasapis, \& Bergman, 1997). Patients with PDs may not have necessary and sufficient insight for true evaluation of their personality characteristics and outcomes of these characteristics. Due to different reasons, mental patients have shown false positive reports about their mental health; and they have confirmed this response set style on the prediction of self-reports inventories.

Charter and Lopez (2002) reported that MCMI-III Scale X and the Clinical Personality Pattern scales were no useful in discovering or identifying random responders.

Symptoms and signs of PDs high overlap with together. So differentiation of them each other is difficult (Zimmerman, 1994). Clinicians identify over a PD for a patient (Dolan, Evans, \& Norton, 1995). The PDs might interfere with the treatment of clinical syndromes (Dadfar, Atef Vahid, Kazemi, \& Kolivand, 2014). The PD could predict symptoms after treatment of addiction (Jansson, Hesse, \& Fridell, 2008). Malakouti, et al (2001) examined the impact of the comorbidity of PDs with the obsessive-compulsive disorder on the medical treatment of patients suffering from both. The MCMI-I1 was used. The findings demonstrated that 1) there was no significant difference in the severity of post-treatment obsession among the two groups, and that medical treatment significantly reduced obsession in both groups; 2) there was no significant difference in the severity of pre-treatment obsession among the two groups.

Dadfar, et al (2002) using MCMI-II, examined impact of pharmacological treatment on PDs of obsessive-compulsive patients. They indicated that no significant difference was found in the number of PDs diagnosed before and after treatment in either group of obsessive-compulsive patients (with and without PDs). As a result of a personality trait comparison, a significant difference was indicated between the aforementioned groups before and after treatment. Pharmaceutical treatment is more likely effective in bringing about changes in personality traits of obsessive-compulsive patients. Such an impact is either influential in alteration of the ways by which this illness is manifested or by affecting personality traits directly.

Gharraee, and Afkham Ebrahimi (1999) studied the code types of the Farsi version of MCMI-II in outpatients/inpatients with diagnosis of schizophrenia, mood disorders and substance related disorders. The findings showed there was a specific code type for Axis I disorders.

There was one study in Iranian non-clinical sample Ghaderi, Mostafaei, Bayazidi, and Shahnazari (2016) reported that on the MCMI-III, prevalence of PDs among college students were Schizoid (0.51\%); Avoidance (1.28\%), Dependent (1.79\%); Histrionic (2.31\%); Narcissist (2.82\%); Antisocial (1.02\%); Aggressive abuser (1.79\%); Compulsive (3.85\%); Passive aggressive (3.08\%); Schizotypal (0.77\%); Borderline $(2.57 \%)$; and Paranoid (1.54\%). On the MCMIIII, five-factor personality Costa and McCrae's NEO-FF-I, there were a positive correlation between schizoid, avoidant, dependent, schizotypal, borderline and paranoid PDs with Neuroticism factor; negative correlation between schizoid, avoidant and schizotypal PDs with extraversion factor; positive correlation between histrionic disorders and extraversion; negative correlation between dependent PD and Openness factor; negative correlation between narcissistic, antisocial and paranoid PDs with agreeableness factor; negative correlation between antisocial, passive-aggressive and borderline PDs with accountability factor; and positive correlation between accountability factor and compulsive PD.

The present study showed that the most frequent of moderate clinical syndromes were Anxiety (A), and Dysthymia (D), and the severe syndromes was Thought Disorder (SS); with double codes of clinical syndromes were Anxiety- Post-Traumatic Stress Disorder (AR).

On the findings of a systematic review in Iran, Farhoudian, Sharifi, Amini, Basirnia, Mesgarpour, et al (2007), revealed prevalence of psychiatric disorders was between from $1.9 \%$ to $58.8 \%$. On the DSM clinical interview and MCMI-II, Dadfar, Dadfar, and Vafa (2009) showed that the most 
frequent of clinical syndromes in GID patients were Anxiety (A), and Dysthymia (D). Ahmadvand, Sepehrmanesh, Ghoreishi, and Afshinmajd (2012) reported that prevalence of psychiatric disorders in Kashan, Iran was $29.2 \%$; mood disorders (9.3\%), MDD (8.2\%); anxiety disorders (4.7\%), generalized anxiety disorder (7.2\%); comorbid psychiatric disorders (7.8\%); women with psychiatric disorders (35.5\%), and men $(21.2 \%)$. On DSM-IV Checklist to clinical interviews were mood disorders $(32.1 \%)$, anxiety disorders $(25.6 \%)$, psychotic disorders $(4.2 \%)$, dissociative disorders (3.4\%), and other psychiatric disorders $(23.7 \%)$.

On three national scale surveys in Iran, using various diagnostic instruments in 1998, 2007 and 2010, prevalence of mental disorders were $21 \%, 17.10 \%$ and $23.6 \%$, respectively; and prevalence of mental disorders in Tehran in 1997, 2007 and 2012 , were $21.5 \%, 34.2 \%$ and $39.6 \%$, respectively (Noorbala, Damari, \& Riazi-Isfahani, 2014). On the General Health Questionnaire (GHQ-28), some studies showed prevalence of mental disorders is increasing in Iran (Noorbala, \& Akhondzadeh, 2015).

There were significant differences between women and men patients. Women showed more faking-bad. Depressive, Passive-Aggressive (Negativistic) (8A), Self-Defeating (8B) and Borderline (C) PDs were the most common in women than men. Compulsive PD was the most common in men compare to women. Anxiety, Somatoform (H), Bipolar: Manic (N), Dysthymia (D), and Post-Traumatic Stress Disorder (R), Thought Disorder (SS), and Major Depression (CC) were the most common in women than men.

On the GHQ-28 in Tehran in the 1998, 21.5\% of people had mental disorders (27\% women and $14.9 \%$ men); and in $2011,39.6 \%$ (37.4\% of men and $43.1 \%$ of women). Anxiety symptoms were higher than somatization, depression, and social dysfunction. Correlates of mental disorders were age, unemployment, illiteracy and divorced or widowed (Noorbala, Bagheri-Yazdi, Vaez-Mahdavi, Asadi-Lari, Faghihzadeh, et al, 2014).

Walsh, Hasin, Keyes, and Koenen (2016) reported association of gender-based violence (GBV) with Schizoid and Borderline PDs in U.S. women.

We concluded that the prevalence of diagnoses personality patterns and clinical syndromes in psychiatric outpatients is high and this should be taken into account in the assessment and treatment planning of these patients.

We found comorbidity between diagnosis of PDs and clinical syndromes on the basis of MCMI-III code types. Comorbid Axis I and Axis II disorders can complicate and difficult treatment for a mental patient. Therefore, assessment of compliance of medication orders is necessary and probe psychotherapy in the treatment plan of overlapping disorders should be included.

The study has some limitations including using of available sample and lack of random sample; lack of control groups for example psychiatric inpatients, psychical patients, normals; and possibility of comorbidity of other mental disorders with main diagnosis.

Diagnostic function of psychological tools such as MCMI-
III is judged through relationship between a psychometric index for a specific disorder; and an external criterion for assessed disorder (determined by clinical interview or diagnostic interview). So, convergent validity of Structural Clinical Interviews for DSM Axis I and Axis II (SCID-I and SCID-II) and MCMI-III profiles in diagnosis of personality disorders and clinical syndromes; also diagnostic validity of a clinician (a psychiatrist or a clinical psychologist) according to DSM-IV and MCMI-III are suggested. Using a combined approach in classification that reflects two approaches of psychiatry and psychometric methods is superior to current approach.

It is possible that MCMI-III was used in acute phase of Axis I syndromes. In such conditions prevalence of personality disorders on the MCMI-III could be more estimated. Probability of over reporting of clinical syndromes in patients who are in acute phase should be controlled with screening of them using $\mathrm{X}$ Disclosure scores of MCMI-III.

Research on the MCMI-III using item response theory (IRT)- known as latent trait theory, strong true score theory, or modern mental test theory-, is recommended. Diagnosis of PDs and clinical syndromes using the MCMI-IV in an Iranian clinical sample is proposed. Clinical epidemiological studies, community-based studies, should be based on standardized evaluations for example using of clinical diagnostic interviews; unstructured clinical interviews, semistructured interviews, rigorous semi-structured clinical interview, the International Personality Disorder Examination (IPDE). Attempt to understand meaning of clinical syndrome and sociodemographic correlates for patient's personality functioning is necessary.

\section{Conflict Interests}

The authors declare that they have no competing interests.

\section{Financial Disclosure}

The authors declared that this study has received no financial support.

\section{References}

[1] Afkham Ebrahimi A, Daneshamooz B. (2000). The comorbidity depression and personality disorders. Iranian Journal of Psychiatry \& Clinical Psychology (IJPCP), 5(3): 22-30.

[2] Afkham Ebrahimi A, Salehi M. (2000). Convergent validity of clinical and structural interview findings and MCMI-II profiles in diagnosis of personality disorder. Iranian Journal of Psychiatry \& Clinical Psychology (IJPCP), 6(2 \& 3): 79-87.

[3] Aghaei, A, Golparvar, M. (2014). Prevalence of personality disorders symptoms among male high school students in Isfahan, Iran. European Journal of Psychology \& Educational Studies, 1: 22-29. 
[4] Ahmadvand A, Sepehrmanesh Z, Ghoreishi FS, Afshinmajd S. (2012). Prevalence of psychiatric disorders in the general population of Kashan, Iran. Archives of Iranian Medicine, 15(4): 205-209.

[5] American Psychiatric Association (1994). Diagnostic and Statistical Manual of Mental Disorders (4th ed) (DSMIV). Washington, DC: APA.

[6] American Psychiatric Association. (2013). Diagnostic and Statistical Manual of Mental Disorders, Fifth Edition (DSM5), American Psychiatric Association, Arlington.

[7] Bernstien DP, Kasapis C, Bergman A. (1997). Assessing axis II disorders by informant interview. Journal of Personality disorder, 11: 158-167.

[8] Charter RA, Lopez MN. (2002) Millon Clinical Multiaxial Inventory (MCMI-III): the inability of the validity conditions to detect random responders. Journal of Clinical Psychology, 58(12): 1615-1617.

[9] Chegini M, Delavar A, Gharraee B. (2013). Psychometric characteristics of Millon Clinical Multiaxial Inventory-III. Journal of Modern Psychological Research (JMPR), 8(29): 135-162.

[10] Dadfar F, Dadfar M, Vafa F. (2009). Clinical syndromes in patients with gender identity disorder (GID). Paper presented at the Third National Congress of Family and Sexual Disorders. Shahed University, 2009. 1-3 November, Tehran, Iran.

[11] Dadfar M, Bahrami F, Dadfar F, Younesi SJ. (2010). Reliability and validity of the Temperament and Character Inventory. Journal of Rehabilitation, 11(3): 15-24.

[12] Dadfar M. (1997). Comorbidity of personality disorders in obsessive-compulsive patients compare with normals. Master thesis in clinical psychology, Tehran Psychiatric Institute, Iran University of Medical sciences, Teharn, Iran.

[13] Dadfar M, Kalibatseva Z. (2016). Psychometric properties of the Persian version of the short Beck Depression Inventory with Iranian psychiatric outpatients. Scientifica, 2016:8196463. doi: 10.1155/2016/8196463. Epub 2016 May 17.

[14] Dadfar M, Atef Vahid MK, Kazemi H, Kolivand PH. (2014). Diagnostic indexes in tests of psychology. Mirmah Publication, Tehran, Iran.

[15] Dadfar M, Malakouti K, Bolhari J, Mehrabi F. (2002). The impact of pharmacological treatment on personality disorders of obsessive-compulsive patients. Iranian Journal of Psychiatry and Clinical Psychology (IJPCP), 8(1): 76-87.

[16] Dadfar M, Yekeh Yazdandoost R, Dadfar F. (2009). Study of personality patterns in patients with dender identity disorder (GID). Iranian Journal of Forensic Medicine (IJFM), 15(2): 96-99.

[17] De Bernier GL., Kim YR, Sen P. (2014). A systematic review of the global prevalence of personality disorders in adult Asian populations. Personality and Mental Health, 8(4): 264275 .

[18] Dolan B, Evans C, Norton K. (1995). Multiple axis-II diagnosis of personality disorder. British Journal of Psychiatry, 166: 107-112.
[19] Eftekhar Ardebili M, Dadfar M, Karimi Kaisami E. (2004). Comorbidity of psychiatric disorders in psychiatric outpatient clinic. Iranian Journal of Psychiatry and Clinical Psychology (IJPCP), 10 (1 \& 2): 11-21.

[20] Eshghabadi S. (2011). Comparison of psychometric characteristics of MCMI-III scales and MMPI-2 scales in Semnan city. Thesis of MS in psychology: Social Sciences School, Islamic Azad University, Branch of central Tehran.

[21] Farhoudian A, Sharifi V, Amini H, Basirnia A, Mesgarpour B, Mansouri N, Amin-Esmaeeli M, Salesian N, Mohammadi MR, Yousefi-Nooraie R, Rahimi-Movaghar A. (2007). Prevalence of psychiatric disorders in Iran: A systematic review. Iranian Journal of Psychiatry, 2: 137-150.

[22] Ghaderi D, Mostafaei A, Bayazidi S, Shahnazari M. (2016). Investigating the prevalence of personality disorders and its relationship with personality traits among students. International Journal of Medical Research \& Health Sciences, 5(4): 119-126.

[23] Gharraee B, Afkham Ebrahimi A. (1999). The code types of MCMI-II in patients with axis I disorders. Iranian Journal of Psychiatry \& Clinical Psychology (IJPCP), 5(1 \& 2): 92-99.

[24] Grant BF, Chou SP, Goldstien RB, Huang GH, Huang B, Stinson FS, Saba TD, Smith SM, Dawson DA, Pulay AJ, Pickening RP, Ruan WJ. (2008). Prevalence, correlates, disability, and comorbidity of DSM-IV borderline personality disorder: results from the Wave 2 national Epidemiologic Survey on Alcohol and Related Conditions. Journal of Clinical Psychiatry, 69(4); 533-545.

[25] Groth-Marnat G, Wright AJ. (2016). Handbook of Psychological Assessment (6th Edition). John Wiley \& sons, Inc.

[26] Grove WM, Vrieze SI. (2009). An exploration of the base rate scores of the Millon Clinical Multiaxial Inventory-III. Psychological Assessment, 21(1): 57-67.

[27] Hills HA. (1995). Diagnosing personality disorders: an examination of MMPI-2 and MCMI-II. Journal of Personality Assessment, 65: 21-35.

[28] Hopwood CJ, Bornstein RF. (2014). Multimethod clinical assessment. The Gilford Press.

[29] Hsu LM. (2002). Diagnostic validity statistics and the MCMIIII. Psychological Assessment, 14(4): 4410-4422.

[30] Huang Y, Kotov R, de Girolamo G. et al (2009). DSM-IV personality disorders in the WHO World Mental Health Surveys. British Journal of Psychiatry, 195(1): 46-53.

[31] Inch R, Crossley M. B. (1993). Diagnostic utility of the MCMI-I and MCMI-II with psychiatric outpatients. Journal of Clinical Psychology, 49(3): 358-366.

[32] Jonson I, Hesee M, Fridell M. (2008). Personality disorder features as predictors of symptoms five years post-treatment. American Journal on Additions, 17(3): 172-175.

[33] Khajeh Mogahy N. (1993). Preliminary preparations of the Persian form of MCMI-II in Tehran city. Master thesis in clinical psychology: Tehran Psychiatric Institute.

[34] Lenzenweger MF, Lane MC, Loranger AW, Kessler RC. (2007). DSM-IV personality disorders in the National Comorbidity Survey Replication. Biological Psychiatry, 62(6): 553-567. 
[35] Libb JW, Murray J, Alarcon RD. (1992). Concordance of the MCMI-II, the MMPI, and axis I discharge diagnosis in psychiatric inpatients. Journal of Personality Assessment, 58: 680-690.

[36] Malakouti K, Mehrabi F, Bolhari J, Dadfar M. (2001). The impact of personality disorders on medical treatment of obsessive compulsive patients. Iranian Journal of Psychiatry and Clinical Psychology (IJPCP), 69(4): 13-23.

[37] Martin J, Walcott G, Clarke TR, Barton EN, Hickling FW. (2013). The prevalence of personality disorder in a general medical hospital population in Jamaica. West Indian Medical Journal, 62(5): 463-467.

[38] Mazaheri Meybodi A, Hajebi A, Ghanbari Jolfaei A. (2014). The frequency of personality disorders in patients with gender identity disorder. Medical Journal of the Islamic Republic of Iran (MJIRI), 28(90): 1-6.

[39] Millon Clinical Multiaxail Inventory-III (MCMI-III) FAQs (2014). When is it appropriate to use the MCMI-III test? OMICS International Publishing Group, Available at http: esearch.omicsgroup.org/index.php/Millon_Clinical_Multiaxial _Inventory.

[40] Millon T. (2008). The logic and methodology of the Millon inventories. Cross-cultural personality assessment. In G. J. Boyle, G. Matthews, \& D. H. Saklofske (Eds.). Sage handbook of personality theory and assessment. Vol. 2: Personality theory and assessment. Los Angeles, CA: Sage.

[41] Millon, T, Davis R, Millon C. (1997). Diagnostic validity of MCMI-III. Journal of Personality Assessment, 68: 69-88.

[42] Millon T, Davis R, Millon C. (1997). Millon Clinical Multiaxial Inventory-III (MCMI-III) manual. Bloomington, MN: Pearson Assessments.

[43] Millon, T., Grossman, S., \& Millon, C. (2015). MCMI-IV: Millon Clinical Multiaxial Inventory Manual (1st ed.). Bloomington, MN: NCS Pearson, Inc

[44] Millon, T., Millon, C., Davis, R., \& Grossman, S. (2009). MCMI-III Manual (Fourth ed.). Minneapolis, MN: Pearson Education, Inc.

[45] Newton-Howes G, Tyrer P, Anagnostakis K, Cooper S, Bowden-Jones O, Weaver T; COSMIC study team. (2010). The prevalence of personality disorder, its comorbidity with mental state disorders, and its clinical significance in community mental health teams. Social Psychiatry and Psychiatric Epidemiology, 45(4): 453-460.

[46] Noorbala AA, Akhondzadeh Sh. (2015). Mental health study process into prevalence of mental disorders in Iran. Archives of Iranian Medicine, 18(2): 76-84.

[47] Noorbala AA, Bagheri-Yazdi SA, Vaez-Mahdavi MR, AsadiLari M, Faghihzadeh S, Mohammad K, Haeri-Mehriz AA, Parsaeia M. (2014). Mental health changes in Tehran during a 12-year period: Comparing national health and disease survey in 1999 and equality project in 2011. Daneshvar Medicine Journal of Shahed University, 113: 37-45.

[48] Noorbala AA, Damari B, Riazi-Isfahani S. (2014). Evaluation of mental disorders incidence trend in Iran. Daneshvar Medicine Journal of Shahed University, 112: 1-11.

[49] Parvizi Fard AA, Birashk B, Atef Vahid MK, Shakeri J. (2001). Comorbidity of mood and anxiety disorders and substance abuse among treatment-seeking addicts and normal individuals. Iranian Journal of Psychiatry and Clinical Psychology (IJPCP), $7(1 \& 2): 45-55$.

[50] Piersma LL, Boes JL. (1998). MCMI-III as a treatment outcome measure for psychiatric inpatients. Journal of Clinical Psychology, 53(8): 825-831.

[51] Retzlaff P. (1996). MCMI-III validity: Bad test or bad validity study. Journal of Personality Assessment, 66: 431-437.

[52] Retzlaff P, Stoner J, Kleinsasser D. (2002). The use of the MCMI-III in the screening and triage of offenders. International Journal of Offender Therapy and Comparative Criminology, 46(3): 319-332.

[53] Sadeghirad B, Haghdoost AA, Amin-Esmaeili M, Ananloo ES, GHaeli P, Rahimi-Movaghar A, Talbian E, Pourkhandari A, Noorbala AA, Barooti E. (2010). Epidemiology of major depressive disorder in Iran: a systematic review and metaanalysis. International Journal of Preventive Medicine, 1(2): $81-91$

[54] Salehi M, Malekian A, Haghighi M, Jahangard L, Rahimi E. (2008). Personality disorders in treatment- seeking substance dependent patients. Iranian Journal of Psychiatry and Behavioral Sciences (IJPBS), 2(2): 10-14.

[55] Sharifi AA. (2007). Millon Clinical Multiaxial Inventory-III (MCMI-III) manual. Tehran, Psychometric Publication.

[56] Sharifi AA, Moulavi H, Namdari K. (2008). The validity of MCMI-III scales. Knowledge \& Research in Applied Psychology, 34: 27-38.

[57] Sharifi V, Amin-Esmaeili M, Hajebi A, Motevalian A, Radgoodarzi R, Hefazi M, Rahimi-Movaghar A. Twelvemonth Prevalence and Correlates of Psychiatric Disorders in Iran: The Iranian Mental Health Survey, 2011. Archives of Iranian Medicine, 18(2): 76-84.

[58] Thuo J, Ndetei DM, Maru M. (2008). The prevalence of personality disorders in a Kenyan inpatient sample. Journal of Personality Disorder, 22: 217-220.

[59] Tyrer P, Mulder R, Crawford M, Newton-Howes G, Simonsen E, Ndetei D, Koldobsky N, Fossati A, Mbatia J, Barrett B. (2010). Personality disorder: a new global perspective. World Psychiatry, 9(1): 56-60.

[60] Walsh K, Hasin D, Keyes KM, Koenen KC. (2016). Associations between gender-based violence and personality disorders in U.S. women. Personality disorders: Theory, research, and treatment, 7(2): 205-210.

[61] Zhang T, Wang L, Good M-J,BJ, Chow A, Dai Y, Yu J, Zhang H, Xiao Z. (2012). Prevalence of personality disorders using two diagnostic systems in psychiatric outpatients in Shanghai, China: A comparison of uni-axial and multi-axial formulation. Social Psychiatry and Psychiatric Epidemiology, 47(9): 14091417.

[62] Zimmeraman M. (1994). Diagnostic personality disorders are view of issues and research methods. Archives of Psychiatry, 51: 225-245.

[63] Zimmerman M, Rothschild L, Chelminski I. (2005). The prevalence of DSM-IV personality disorders in psychiatric outpatients. American Journal of Psychiatry, 162(10): 19111918. 